\title{
A Study on Computer Teaching Based on Computational Thinking
}

\author{
https://doi.org/10.3991/ijet.v11i12.6069 \\ Meng Wang and Yufeng Wang \\ School of Medical Information Engineering, JiNing Medical University, RiZhao, China
}

\begin{abstract}
The concept of computational thinking has caused wide public concern over the world. How to cultivate students' computational thinking and creative ability becomes a common question. This paper proposes some suggestions about the curriculum provision of theory courses and experimental teaching of computer science and technology.
\end{abstract}

Index Terms-Computational Thinking, Integration of Courses, Computer Teaching

\section{INTRODUCTION}

The proposal of the concept of computational thinking has initiated a heated discussion around the world and it directly brought about many projects funded by NSF (National Science Foundation). Carnegie Mellon University held a serial of seminars on computation thinking; CSTA(Computer Science Teacher Association) issued a report of "computational thinking: an instrument for solving questions in all classes" and gained support from Microsoft Corporation; Moreover, BCS(British Computer Society) started a workshop on computation thinking and put forward European action program.

In China, many experts and scholars, including Wang Feiyue, a professor from Institution of Automation of Chinese Academy of Sciences, Li Guojie, a academician from Institution of Computation of Chinese Academy of Sciences, Chen Guoliang, another academician from University of Science and Technology of China, Dong Rongsheng, a professor from Guilin University of Electronic Technology, Zhu Yazong, a professor from National University of Defense Technology, to name but a few, have made a helpful exploration in computational thinking.

\section{WhAT Is COMPUTATIONAL THINKING?}

Zhou Yizhen, a professor from Carnegie Mellon University, defined computational thinking in Communications of the ACM in 2006. It is assumed that computational thinking is a serial of thinking actions that cover computer science, including making use of basic concepts of computer science to solve problems, design systems and comprehend human behaviors and so on[1]. The essence of computational thinking is abstraction and automation [2]. Just as all the people possess the ability of reading, writing and calculating, computational thinking is the thinking ability that everybody must have, not limited to computer scientists.

The winner of Turning Award in 1972, Edsger W. Dijkstra said, "The instruments we use affect our mode and habit of thinking and thereby deeply affect our think- ing ability." Appearance of computers triggered intelligent thinking. Professor Zhou especially promoted the development of computers from instruments to thinking into "a universal recognition and a widespread skill". In a sense, this also means computer science has changed from advancing front into basic popularity[3,4].

\section{COMPUTER TEACHING RESEARCH BASED ON COMPUTATIONAL THINKING}

\section{A. Cultivation of Computational Thinking Ability}

To cultivate students' computational thinking ability, enhancing students' self-study ability is the first step. After entering the university, students are faced with the rapid developing computer science. So it will be unwise to still depend on learning styles in middle school. The master may teach, but progress is up to the hard work of the individual. What is learnt in the classroom only covers the basic theories and skills that construct the whole framework, while a mass of new technology, methods and application require an individual to actively discover to accumulate and enrich his or her knowledge framework. Especially, in the present, Network information is so developed, information transferring is so convenient, and various resources are so easy to get that it is much possible to stay at home and know the world events.

Secondly, questioning ability should be strengthened. Li Zhengdao said, "the most important point of personnel training is to cultivate their creativity." With questioning, creativity comes into being. During teaching, teachers should require students to keep a healthy suspicious attitude, not to limited to the solution given by teachers and textbooks. Teachers should consciously encourage students to speak out, think hard, and bravely put forward their opinions. The spoon-feeding way of teaching in which teachers give lectures and students listen should be changed[5].

Thirdly, narrow idea of computer as instrument should be abandoned. Computational thinking aims to help students construct a thought to solve problems by way of computer technology and understand the possibility of solving problems. If the major of computer equals to a simple major of programming, computers being the same as the pure advanced instruments, and cultivating students' ability of proposing and solving problems being neglected, the original thought of computational thinking will be deviated.

\section{B. Integration of Course Contents}

\section{1) Focusing on coherence among course contents}

According to materialistic dialectics, things are connected universally. Discussion and development of a giv- 


\section{SHORT PAPER \\ A STUdy ON COMPUTER TEACHING BASED ON COMPUTATIONAL THINKING}

en course without considering other courses is segmentary. In the whole topological structure of a major, every course has its relatively fixed coordinate and its connection with the previous and following contents. If these connections are neglected, course development will possibly become water without a source and trees without roots.

For example, as for the course of data structure and its guide course $\mathrm{C}$ language programming, if the knowledge points involved in data structure are not enhanced in the teaching of $\mathrm{C}$ language programming, it will bring in teaching and learning of data structure lots of obstacles, which are especially obvious in experimental teaching of data structure. Tree and Graph are involved in teaching both data structure and discrete mathematics. However, teaching focus of this section in two courses is usually not clear, leading to repetition of teaching contents and a waste of resources. The same problem also occurs in $\mathrm{Ob}-$ ject-oriented programming and JAVA programming. Besides, after learning $C$ programming, the following programming courses may focus on data structure and analysis of algorithm and lay emphasis on abstracting and solving problems, rather than continuous discussion about details of grammar, which attend actually to trifles and neglect the essentials. Moreover, the same problems also exist in the coherence between programming courses and database principles, software engineering and Computer composition principle.

\section{2) Keeping progressiveness of course contents}

The latest research findings need to be introduced into teaching, and students should be guided to focus on its development. The use of textbooks has their fixed life cycles, while the discipline develops constantly. Besides, teachers are not supposed to serve for examinations in their teaching. Since 2008, postgraduate entrance examination for computer major has been unified examination, and examination courses and contents are the same over the country. In such a situation, some teachers began to teaching selectively. Contents relevant to postgraduate entrance examination become the key points, while those irrelevant to the exam are taught simply or even put aside, not to mention discuss the front contents. Taking the course of operating system as an example, we know that Multi-core processors have been wildly adopted, but they are rarely mentioned in the textbook and teaching contents also only focus on single-core processors. Actual teaching contents usually cannot cover relevant knowledge because of the limitation of learning periods. However, teachers should at least definitely require students to study this section by themselves, add relevant reading materials or try to offer the optional course and opening experiments to support students to extend their knowledge. On the other hand, teachers must learn new knowledge and keep an eye on the latest findings, so as not to become a frog in a well.

\section{3) Applying theories into practice}

Teaching theories purely may make students feel dull because they don't know their usage. Under these circumstances, teachers give students the impression of only empty talking and finally lead to the failure of teaching. We should apply teaching contents into practice to help students to understand. For instance, a pupil goes to school in the morning, and he will put all the things that he need the whole day into the bag, which is the same as prefetching and caching. When we pay in the market, we'll choose one queue to join, which is similar to multi server performance modeling. This requires us to frequently observe and think, because scientific questions come from actual life.

\section{Design of experimental teaching}

The core of experimental teaching is to cultivate students' ability of practice and creativity. Computer major is one of high practice. Our fanciers are finally achieved through machines, or they are illusory. Experimental teaching not only testifies theories, but also cultivates students in discovering, analyzing and solving problems. What's more, the positive and negative feedback on theories can help us to correct theory teaching content and rhythm.

Compared with the arrangements of theory content, design of experiments seems more difficult. Our experimental teaching adopts the strategy of " $3+2$ ", in which " 3 "means construct of course experiments, course design and graduation design.

\section{1) Fixing the title}

Firstly, practice of course experimental content should be emphasized to cultivate students' ability of solving problems. To take data structure as an example, we can take advantage of stack and queue to solve the problem of management of parking lots. The problem of project cost such as laying gas pipes in urban districts, course arrangement system and farmer river-crossing all involve the Minimum Cost Spanning Tree of Graph, Topological Sort and the Shortest Path. Furthermore, teachers should guide students to play a subjective role in learning and encourage them to seek for practical cases in daily life or attract them to directly take part in teachers' research projects in order to cultivate their ability of solving practical problems.

Secondly, experimental projects should be adjusted to students of different proficiency. Otherwise, students with strong ability will feel dull while students with weak ability will also lose heart. For example, in practical experiment of stack, all students are required to achieve the conversion of different number system and the test of bracket matching, while top students can choose to try the problem of Maze solving and expression evaluation after they finish the basic requirements. Experimental teaching adjusting to different students can help them gain what they need and develop their ability.

\section{2) Course design}

Course design is the integrated training for software design. Students are required to improve their ability of programming design and master scientific working methods. It aims to help students to master the method of organizing data according to the features of data and use the computer to deal with the practical problems in real world. In designing the course, teachers should carefully choose some integrative and designable problems, and require student to develop their ability of self-study, draw up a reasonable schedule for course design and check the fulfillment of their plans.

\section{3) Graduation design}

Graduation design is a systematic project. In the procedure of graduation design, apart from strengthening organization and supervising the procedure, teachers' great concern should be the last moment of experimental teach- 
ing, because this is the integration and simulation of what they have learnt during four years and also warming-up before they get to work. The integrated training will make students more confident and relaxing when they are confronted with social competition. How to deepen the experimental teaching and help students to improve themselves is worth consideration and discussion.

"2"means making reasonable use of out-campus resources.

(1)competitions instead of practice

Students should be encouraged to actively participate in ACM competition, Qilu Software Competition and other various competitions. Compared with some superiors, they will find their own disadvantages. After all, the experimental projects finished on campus cannot match the competitions not only in difficulty but also in intensity.

(2) Cooperation between universities and enterprises

Cooperation between universities and enterprises should be strengthened and the gap between teaching and market requirements should be narrowed, which can either solve teachers' problem of lacking in experience of practical projects or help students to finish role shift from campus to working place.

\section{CONCLUSIONS}

Nowadays, Computational thinking is a very important concept attracting wide attention in computer field and it is also an important research project in computer teaching. In the future, computer teaching will focus on cultivating students' computational thinking ability, which is adaptable to all majors. But, in the practice, how to promote students' computational thinking ability and cultivate students' creative ability is still under exploration.

Based on practical teaching experience and background of computational thinking, we give consideration to course contents of computer major and experimental teaching. The cultivation of computational thinking not only depends on an individual teacher or a certain course, rather, it requires all teachers cooperate with each other and enhance students' ability consciously.

\section{ACKNOWLEDGMENT}

1. The authors confirm that this article content has no conflict of interest.

2. Thanks for the help of Yufeng Wang.

\section{REFERENCES}

[1] Wing J M, "Computational thinking”, Communications of ACM, 2006, Vol.3, No.49, pp. 33-35. https://doi.org/10.1145/111 $\underline{8178.1118215}$

[2] Wing J M, "Computational thinking and thinking about computing”, Philosophical Transactions of the Royal Society, 2008, Vol.366, pp. 3717-3725. https://doi.org/10.1098/rsta.2008.0118

[3] ISTE\&CSTA, Computational thinking teaching in K-12 Education:teacher resources, second edition(2011) [DB/OL].
[D http://csta.acm.org/Curriculum/sub/CurrFiles/472.11CTTeacherRe sources_2ed-SP-vF.pdf, 2013-05-12.

[4] Jackson J. and Moore L, The Role of Computational Thinking in the 21 st Century[DB/OL].

http://www.appropriatetech.net/files/Papers_Green_Economy_and _Innovation.pdf,2013-05-10.

[5] Y. F. Wang, Z. B. Liu, "Study and Practice on Bilingual Teaching of Data Structure Course", Computer Education, 2009, Vol.10, pp.122-124.

\section{AUTHORS}

Meng Wang is with the School of Medical Information Engineering, JiNing Medical University, RiZhao, ShanDong Province, CO 276826 China (e-mail: apollo636@163.com). He received the B.S. and M.S. degree in computer science from Shandong Normal University, China in 2003 and 2006.

Yufeng Wang is with the School of Medical Information Engineering, JiNing Medical University, RiZhao, ShanDong Province, CO 276826 China (e-mail: wyftiger@tom.com). He received his B.S. and M.S. degree in computer science from Chengdu University of Technology, China in 1996 and 2001. He is currently working towards his Ph.D.degree at HuaZhong University of Science and Technology, China.

This work was supported by the Education and Teaching Reform Project of Jining Medical University in 2014 (No.14056 and No.14017).

Submitted, 23 July 2016. Published as resubmitted by the authors on 08 October 2016. 